\title{
Comparison Of Patient Satisfaction Between New Complete Denture Wearers And The Old Ones
}

Zarah Afreen, Shoaib Rahim, Ammarah Afreen, Umer Javed, Aamna Khalil, Sadia Daaniyal

- - - - - - - - - - - - - - - - - - - - - - - - - - - -

ABSTRACT

Objective: To determine the mean satisfaction score for patients with complete dentures and to compare the mean satisfaction score of patients with complete dentures and without past denture experience.

Study design and Setting; It was a cross-sectional study conducted at Watim Dental College, Rawalpindi, from March to August 2018.

Methodology: A total of 98 patients were selected and were asked regarding previous history of denture usage and their experience with the new set of dentures; in terms of function, comfort, appearance and total satisfaction. As a protocol all patients presenting to outpatient department and those patients who fulfilled the criteria were referred to Prosthodontic department for provision of complete dentures by specialist prosthodontist. Data was analysed using SPSS version 20. Descriptive statistics were calculated for both qualitative and quantitative variables. For qualitative variables like gender frequency and percentages was calculated. For Quantitative variables like age, score of function, comfort, appearance and total satisfaction mean and standard deviation were calculated. Mean \pm SD was calculated for satisfaction score among patients with and without past experience of denture usage. Independent sample t-test was used to compare quantitative variables. $\mathrm{P}$ values of less than 0.05 was considered significant.

Results: Mean score of function, comfort, appearance and total satisfaction was greater among the patients with past denture experience as compared to new denture wearers with no past experience of denture wearing.

Conclusion: Past denture experience has significant effect on patient satisfaction with their new complete dentures.

Keywords; Complete denture wearers, patient satisfaction, past denture experience.

\section{INTRODUCTION:}

There is a significant co relation between oral and general health, which subsequently affects the overall quality of life of people especially the elderly people. The oral health of a population can be well indicated by partial or complete edentulism. ${ }^{1}$ One of the major concerns among elderly population worldwide is edentulism, although over the last few years the incidence of complete tooth loss has markedly decreased. ${ }^{2}$ However, the different regions of the world have

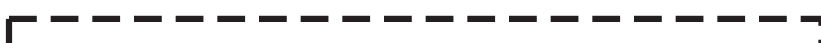

Zarah Afreen

Assistant Professor, Prosthodontics

I Watim Dental College

Email: zarahsufian@yahoo.com

| Shoaib Rahim

Assistant Professor, Prosthodontics

Foundation University College of Dentistry

I

Ammarah Afreen

Assistant Professor, Operative Dentistry

- Watim Dental College

I Muhammad Umer Javed

I Consultant Prosthodontist, Prosthodontics

Federal Govt. Polyclinic, Islamabad

| Aamna Khalil

Assistant Professor, Prosthodontics

Multan Medical and Dental College

Sadia Daaniyal

Senior Registrar, Prosthodontics

I HBS Medical and Dental College

Received: 08-10-2019

I Accepted: 12-12-2019

JBUMDC 2020;10(1):7-11 shown considerable variations in the prevalence of complete edentulism. ${ }^{3}$ Direct consequences of edentulism include impaired masticatory function, discomfort, nutritional deficiencies, poor oral health quality, psychological and social disability. ${ }^{4}$

Conventional complete denture therapies still extensively used and it is not expected to decline in the near future especially in less developed population with limited economic resources. ${ }^{5}$ Rehabilitation with dentures following tooth loss may result in great amount of impact and social implications on the patient. ${ }^{6}$ The ability of the patient to interact with others can also be restored with the help of dentures. ${ }^{7}$ The prosthetic rehabilitation is mainly provided to those who have experienced tooth loss in order to restore function, comfort, aesthetics and oral health. Clinicians believe that supporting tissues can be maintained in good health by means of well-fitting dentures and in this way oral function and self-esteem of the patients can be improved. ${ }^{8}$

Patient satisfaction is considered as one of the most important goals in prosthodontic treatment. The factors which mainly affects the stomatognathic system are the quality of dentures, oral conditions, patient's acceptance towards the dentures, patient's personality and the patient-dentist relationship. ${ }^{9}$ The influence of patient expectations on the patient satisfaction must be determined as it has a crucial effect on the success of the treatment. ${ }^{8}$ Different results were shown in different studies when these factors were examined. Some investigators did not find a significant relationship while 
others did.$^{10,11}$ The success of complete dentures is dependent on multiple factors, patient perception is an important factor for successful treatment. ${ }^{12}$ Satisfaction towards complete dentures may not only be affected by biologic and technical considerations taken into account during fabrication of complete dentures, other parameters may also play an important role. These include age, gender, literacy level, socioeconomic conditions, marital status, patient/professional relationship and psychological factors. ${ }^{13,14}$

Patient satisfaction is also affected by a large number of factors. Previous experience with dentures and age of patient are considered important factors. One study concluded that patients greater than sixty years of age showed greater difficulty in adaptation to the new set of complete dentures than those who were younger than sixty. ${ }^{15}$ The oral mucosal disorders which are frequently associated with aging and denture usage includes denture stomatitis, angular cheilitis, oral fungal infections, and traumatic ulcers. ${ }^{16-18}$

The rationale of this study was to evaluate the effects of denture on patient satisfaction with new set of dentures. One of the important determinants for success of complete denture therapy is past denture experience, therefore it should be considered during evaluation and assessment of completely edentulous patient. This study was aimed to determine the mean satisfaction score for patients with complete dentures and to compare the mean satisfaction score of patients with complete dentures with and without past denture experience.

\section{METHODOLOGY:}

It was a cross-sectional study conducted at Watim Dental College, Rawalpindi, from March to August 2018.

The ethical approval from the hospital ethical committee was obtained prior to the study. The subjects were selected via non-probability consecutive sampling. Inclusion criteria consisted of both male and female patients with age ranging from 35-80 years, who were selected for provision of complete dentures with or without any previous history of denture use. Exclusion criteria consisted of patients with a history of maxillofacial trauma, Parkinson's disease, myasthenia gravis, bulbar palsy, hyposalivation or xerostomia, terminally ill patient, non-cooperative or mentally debilitated patient and patient using antipsychotics or antidepressants, muscle relaxants. As a protocol all patients presenting to the hospital were examined in OPD and those patients who fulfilled the criteria were referred to Prosthodontic department for provision of complete dentures by specialist prosthodontist.

A total of 98 patients were selected for this study based on above mentioned criteria and were asked regarding previous history of denture usage. The dentures were fabricated by a single prosthodontic laboratory technician in the hospital. All subjects were instructed to wear their dentures during waking hours and to remove them before sleeping at night. Oral hygiene instructions were provided. Patients were requested to return after one week after insertion and were interviewed by principal investigator for answering questions which were given in the questionnaire regarding their experience with the new set of dentures, in terms of three categories, that is, function which consisted of drinking, chewing, biting and speaking; comfort which consisted of denture tightness (in both arches), gagging and denture comfort in both arches; and appearance which consisted of shape of teeth, shade of teeth and general appearance. A five- point scoring system (poor $=1$, fair $=2$, good $=3$, very good $=4$ and excellent $=5$ ) was used. Total satisfaction score, out of 60 , was calculated based on the scores in these three categories and filled in the proforma (function score $=20$, comfort score $=25$ and appearance score $=15$ ). Follow up was ensured through telephonic contact.

Data was analysed using SPSS version 20. Descriptive statistics were calculated for both qualitative and quantitative variables. For qualitative variables frequency and percentages was calculated. For Quantitative variables mean and standard deviation were calculated. Mean \pm SD was calculated for satisfaction score among patients with and without past experience of denture usage. Independent sample t-test was used to compare quantitative variables. $P$ values of less than 0.05 was considered significant.

\section{RESULTS:}

A total number of 98 patients were selected for this study out which $\mathrm{n}=52(53.1 \%)$ were male and $\mathrm{n}=46(46.9 \%)$ were female. . The frequency distribution of patients is given in Figure-I. Among these $\mathrm{n}=98$ patients $52.04 \%(\mathrm{n}=51)$ were new denture wearers with no previous denture experience and $47.96 \%(n=47)$ were old denture wearers with previous experience of denture use. Mean+SD Scores for Function, Comfort and Appearance and total satisfaction score were calculated as shown in Table-I.

Independent sample t-test was applied to determine the difference in the scores for function, comfort and appearance for patient who had previous experience with denture wearing and those who had no experience and p-value was calculated as given in Table-II. As can be depicted from the table, the average scores for the patients who were new denture wearers were lower than those who had past denture experience for all tested variables. Independent sample t-test was applied to determine the difference in total satisfaction score between both genders and p-value was 0.024. Independent sample $\mathrm{t}$-test was used to determine the difference in satisfaction score between age (which was grouped into 35-57 years and 58-80 years for this test) and a p-value of 0.001 was found to be significant.

\section{DISCUSSION:}

Patient satisfaction with their dentures is a complex phenomenon which is influenced by various factors. In addition to psychological factors, various other factors have an influence on patient satisfaction. ${ }^{19}$ The concept of success 
Zarah Afreen, Shoaib Rahim, Ammarah Afreen, Umer Javed, Aamna Khalil, Sadia Daaniyal

of dentures were judged by the dentists and patients in a different way. Technical standards are considered the key point for the success of denture by the dentist. In contrast to this, patients evaluate them from the viewpoint of personal satisfaction. The patients who were well satisfied in their lives are also more satisfied with their dentures. ${ }^{20}$ A patient self-assessment questionnaire allows patients an opportunity for discussing and sharing their viewpoint with their clinician,

Figure-I: Histogram Showing Frequency Distribution of Patients

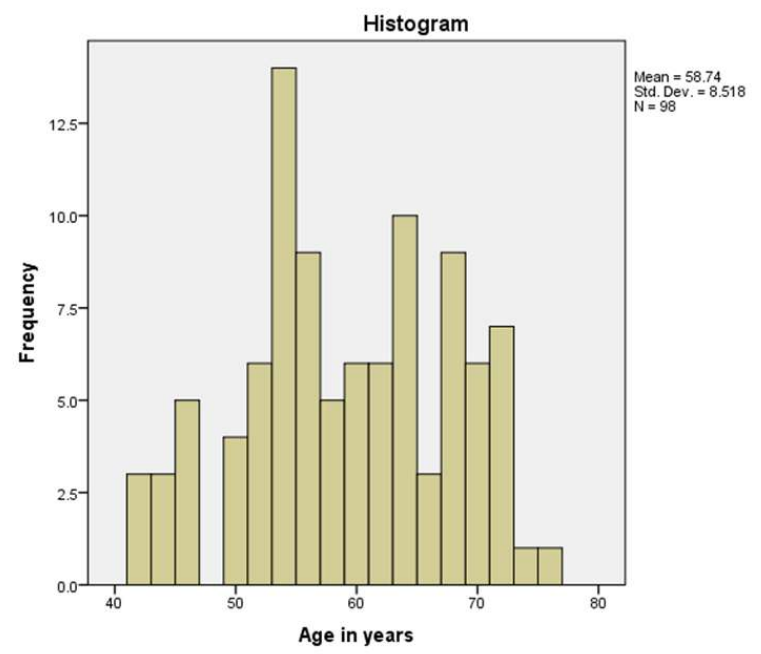

Table-I: Mean and Standard Deviation of Scores For Total Satisfaction Comprising Of Function, Comfort And Appearance

\begin{tabular}{|l|ll|}
\hline \multirow{2}{*}{ Category } & \multicolumn{2}{|c|}{ Score } \\
\cline { 2 - 3 } & Mean Standard Deviation \\
\hline Function & 3.01 & 0.902 \\
\hline Drinking & 2.87 & 0.893 \\
\hline Chewing & 2.87 & 0.949 \\
\hline Biting & 3.36 \\
\hline Speaking & 12.153 & 1.048 \\
\hline Functional Satisfaction & 2.822 \\
\hline Comfort & 3.46 \\
\hline Upper denture tightness & 2.76 & 1.047 \\
\hline Lower denture tightness & 3.46 & 0.850 \\
\hline Gagging & 3.37 & 0.910 \\
\hline Upper denture comfort at rest & 0.817 \\
\hline Lower denture comfort at rest & 2.86 & 0.849 \\
\hline Comfort Satisfaction & 15.877 \\
\hline Appearance & \multicolumn{2}{|l}{3.026} \\
\hline Shape of teeth & 3.31 & 0.913 \\
\hline Shade of teeth & 3.31 & 0.913 \\
\hline General Appearance & 3.57 & 0.952 \\
\hline Appearance Satisfaction & 10.153 & 2.299 \\
\hline Total Satisfaction & 38.193 \\
\hline
\end{tabular}

Table-II: Independent Sample T-Test of Scores For Total Satisfaction Comprising Of Function, Comfort And Appearance Between New Denture Wearers And Old Denture Wearers

\begin{tabular}{|c|c|c|c|c|c|}
\hline \multirow{3}{*}{$\begin{array}{l}\text { Denture Experience } \\
\text { Category }\end{array}$} & \multicolumn{4}{|c|}{ Score } & \multirow{3}{*}{ P-value } \\
\hline & \multicolumn{2}{|c|}{$\begin{array}{c}\text { Old Denture Wearer } \\
\mathrm{N}=47\end{array}$} & \multicolumn{2}{|c|}{$\begin{array}{c}\text { New Denture Wearer } \\
\mathrm{N}=51\end{array}$} & \\
\hline & Mean & $\begin{array}{l}\text { Standard } \\
\text { Deviation }\end{array}$ & Mean & $\begin{array}{l}\text { Standard } \\
\text { Deviation }\end{array}$ & \\
\hline \multicolumn{6}{|l|}{ Function } \\
\hline Drinking & 3.53 & 0.80 & 2.53 & 0.70 & 0.001 \\
\hline Chewing & 3.26 & 0.84 & 2.51 & 0.78 & 0.001 \\
\hline Biting & 3.36 & 0.76 & 2.41 & 0.87 & 0.001 \\
\hline Speaking & 3.89 & 0.78 & 2.86 & 1.02 & 0.001 \\
\hline Functional Satisfaction & 14.021 & 1.95 & 10.431 & 2.37 & 0.001 \\
\hline \multicolumn{6}{|l|}{ Comfort } \\
\hline Upper denture tightness & 3.96 & 0.85 & 3.00 & 1.00 & 0.001 \\
\hline Lower denture tightness & 3.19 & 0.77 & 2.35 & 0.72 & 0.001 \\
\hline Gagging & 3.85 & 0.75 & 3.10 & 0.90 & 0.001 \\
\hline Upper denture comfort at rest & 3.72 & 0.65 & 3.04 & 0.82 & 0.001 \\
\hline Lower denture comfort at rest & 3.15 & 0.75 & 2.59 & 0.85 & 0.001 \\
\hline Comfort Satisfaction & 17.851 & 1.76 & 14.058 & 1.95 & 0.001 \\
\hline \multicolumn{6}{|l|}{ Appearance } \\
\hline Shape of teeth & 3.83 & 0.56 & 2.82 & 0.91 & 0.001 \\
\hline Shade of teeth & 3.77 & 0.69 & 2.88 & 0.88 & 0.001 \\
\hline General Appearance & 4.06 & 0.67 & 3.12 & 0.95 & 0.001 \\
\hline Appearance Satisfaction & 11.617 & 1.26 & 8.803 & 2.21 & 0.001 \\
\hline Total Satisfaction & 43.510 & 3.68 & 33.294 & 6.33 & 0.001 \\
\hline
\end{tabular}


hence it is used in this study. ${ }^{21}$

According to a study by Samara RM, little influence is exerted on patient's acceptance of the new set of dentures by gender variation, although females appear to be a little more critical with their dentures as compared to males, particularly in terms of aesthetics. ${ }^{9}$ In our study a significant difference was noted in the total satisfaction score among males and females, which was not in agreement with a study by Knezovic-Zlataric and colleagues. This difference may be because of the difference in the population ethnicity as their study was conducted on Croatian adults, which further enforces the effect of geographic variability on population satisfaction. Although further studies on larger population may need to be conducted for confirmation. ${ }^{21}$ Current study results are consistent with another study carried out by Rania M Samara, at Princess Ayesha Medical Complex / Royal Medical Services, over a period of two years. ${ }^{9}$ Significantly higher mean scores were recorded in patients who have previous denture experience. The results of this study showed that patients with additional set of dentures exhibited improved function and comfort. In addition to this, patients appear to be more satisfied with their new denture aesthetics as well as they have more realistic expectations regarding aesthetics. Furthermore, the speaking ability also tends to be improved in these patients. ${ }^{9}$

The mean score of total satisfaction in this study was $43.5 \pm 3.68$ for old denture wearer which was much higher than new denture wearers $(33.29 \pm 6.33)$ and it was statistically significant and consistent with scores of another study and was also found to be significant. ${ }^{10}$ According to this study the mean score of function was found to be higher (14.02 \pm 1.95 ) among old denture wearer as compared to new denture wearers $(10.43 \pm 2.37)$. It is found to statistically significant. This result is also comparable to another study in which mean score of function among old denture wearer was higher $(19.30 \pm 1.436)$ as compared to new denture wearer (17.23 \pm 2.54$){ }^{9}$

The mean score of comfort was found to be higher (17.85 \pm 1.76 ) among old denture wearer as compared to new denture wearer $(14.05 \pm 2.05)$. This result is also comparable to another study in which mean score of comfort among old denture wearer was higher $(24.40 \pm 0.836)$ as compared to new denture wearer $(22.56 \pm 2.39) .{ }^{9}$ The mean score of appearance was $11.61 \pm 1.26$ for old denture wearer which is much higher than new denture wearers $(8.80 \pm 2.21)$. Mean score of appearance among the old denture wearer was found to be $14.84 \pm .561$ as compared to new denture wearer $14.59 \pm .959 .{ }^{10}$ This result was not consistent with the result of our study because although the value was found to be higher among the old denture wearer as compared to new denture wearer, the result was not found to be significant.

Another study was conducted at Liaquat University Hospital Hyderabad and Jamshoro to evaluate the factors which influence the patient's satisfaction with removable dentures. Sixty-six patients of both genders were included. More than $55 \%$ of the patients were comfortable with their dentures. 65 to $80 \%$ patients showed their satisfaction in terms of retention, stability, speech, taste, chewing and communication. While $86.7 \%$ subjects experienced no pain or discomfort and $60 \%$ of subjects did not have a foreign body feeling with the use of dentures. Furthermore, $53.3 \%$ felt they will recommend the treatment to others. According to this study, the satisfaction scores were considerably higher in patients who were provided with the set of dentures for the first time. ${ }^{19}$

The limitations of this study included patient over a larger age group were selected, that is, 35-80 years, the status of residual alveolar ridge was not considered and the quality of previous complete dentures were not evaluated or considered in subjects who were old denture wearers. Improved stability and function of prosthesis can be seen in those patients who have an additional set of dentures. It might be due to a more developed neuromuscular control over their dentures. Speaking ability appears to be improved and these patients tend to have more realistic expectations in terms of aesthetics.

\section{CONCLUSION:}

Past denture experience has significant effect on patient satisfaction with their new complete dentures.

\section{REFERENCES:}

1. Hewlett SA, Yawson AE, Calys-Tagoe BN. Edentulism and quality of life among older Ghanaian adults: BMC Oral Health. 2015;15:48

2. Paula LMLLDP, Sampaio AA, Costa JG. The course from tooth loss to successful rehabilitation with denture: Feelings influenced by socioeconomic status: Sage Open Medicine. 2019;7: 1-8

3. Latif TM, Vieira AR. Risk Factors and Comorbidities Associated with Complete Edentulism in Individuals Younger than Fifty Years of Age: J Dent Oral Health. 2017; 4: 1-6.

4. Rajaraman V, Ariga P, Dhanraj M. Effect of edentulism on general health and quality of life: Drug Invention Today. 2018; 10: 549-553.

5. Carlsson GE, Omar R. The future of complete dentures in oral rehabilitation. A critical review. J Oral Rehabil. 2010;37(2): 143-56.

6. Picos AM, DONCA V, 6. Picos A. Prosthetic Rehabilitation in Partially Edentulous Elders - A Case Report: Clujul Med. 2014; 87(3): 203-206.

7. Roumanas ED. The social solution-denture esthetics, phonetics, and function. J Prosthodont. 2009;18(2):112-5.

8. De Lucena SC, Gomes SG, Da Silva WJ, Del Bel Cury AA. Patients' satisfaction and functional assessment of existing complete dentures: correlation with objective masticatory function. J Oral Rehabil. 2011;38(6):440-6.

9. Samara RM. The effect of past denture experience on patient's satisfaction with their complete dentures. Pak Oral Dent J. 2009;29:403-8. 
10. Ellis JS, Pelekis ND, Thomason JM. Conventional rehabilitation of edentulous patients: the impact on oral healthrelated quality of life and patient satisfaction. J Prosthodont. 2007;16(1):37-42.

11. Fenlon MR, Sherriff M, Newton JT. The influence of personality on patients' satisfaction with existing and new complete dentures. J Dent. 2007;35(9):744-8.

12. Ahmed AR, Muneer MU, Hussain MW. Clinical Analysis of Complete Denture Satisfaction Factors: Dentist and Patient Perspective. International Journal of Medical Research \& Health Sciences, 2019, 8(8): 128-34.

13. Miranda BB, Dos Santos MB, Marchini L. Patients' perceptions of benefits and risks of complete denture therapy. J Prosthodont. $2014 ; 23(7): 515-20$.

14. Ntala PC, Niarchou AP, Polyzois GL, Frangou MJ. Screening of edentulous patients in a dental school population using the prosthodontic diagnostic index. Gerodontology. 2010;27(2):114-20.

15. Critchlow SB, Ellis JS. Prognostic indicators for conventional complete denture therapy: a review of the literature. J Dent. 2010;38(1):2-9.
16. MacEntee MI, Glick N, Stolar E. Age, gender, dentures and oral mucosal disorders. Oral Dis.1998;4(1):32-36.

17. Mubarak S, Hmud A, Chandrasekharan S. Prevalence of denture-related oral lesions among patients attending College of Dentistry, University of Dammam: A clinico-pathological study. J Int Soc Prev Community Dent. 2015; 5(6): 506-12.

18. Gautham P, Mallikarjun M, Chakravarthy K. Assessment of denture hygiene maintenance among elderly patients in Nizamabad (Telangana) population: A survey. Journal of Dr NTR University of Health Sciences. 2016;5(4):275-280.

19. Abouelkomsan AM, Butt AM, Dall AQ. Removable partial dentures: Patient satisfaction with associated demographic and biomechanical factors. Pak Oral Dent J. 2012;32(3):56468 .

20. Singh S, Mishra SK, Chowdhary R. Patient expectations and satisfaction with conventional complete dentures: a systematic review. Tanta Dental Journal. 2019;16(2):55-67.

21. Zlataric DK, Celebic A, Valentic-Peruzovic M, Celic R, Filipovic-Zore I, Bauci M. The satisfaction with the removable partial denture therapy in the Croatian adult population. Coll Antropol. 2000; 24(2):485-94. 